Chapter 17

\title{
Emerging Role of Natural Antioxidants in Chronic Disease Prevention with an Emphasis on Vitamin E and Selenium
}

\author{
Manuel Soriano García \\ Additional information is available at the end of the chapter \\ http://dx.doi.org/10.5772/51610
}

\section{Introduction}

The possibility has arisen within the last three decades that major diseases that directly affect humankind worldwide may be preventable by the simple improving the dietary intake of those nutrient substances that have become called "antioxidant nutrients".

There is no doubt that successful prevention is the key to controlling morbidity and mortality from chronic diseases affecting humankind. Prevention provides: the methods to avoid occurrence of disease and most population-based health promotion efforts are of this type; methods to diagnose and treat extant disease in early stages before it causes significant morbidity; methods to reduce negative impact of extant disease by restoring function and reducing disease-related complications; and finally, the methods to mitigate or avoid results of unnecessary or excessive interventions in the health system.

The quality and quantity of diet with respect to the intake of fresh food (fruits, seeds and vegetables) may improve our health and consequently decrease the risk of any disease. Currently, the antioxidant nutrients are the vitamins $C$ and $E$ and $\beta$-carotene. However, it is worthy to mention that these compounds are involved in other functions a part from being antioxidant nutrients.

Selenium (Se), a trace mineral. Is the $34^{\text {th }}$ element and is located between sulfur and tellurium in Group 16 in the periodic table. It is a nonmetallic element and its properties are intermediate between adjacent sulfur and tellurium. It was originally discovered by a German chemist Martin Heinric Klaproth, but misidentified as tellurium. Later, in 1818 a Swedish chemist Jons Jacob Berzelius discovered selenium and was named after the Greek goddess of the moon, Selene [1] and its name was associated with tellurium, a name for earth. He 
observed the element as a deposit following the oxidation of sulfur dioxide from cooper pyrites. It ranks seventieth in abundance among the elements and is distributed in the Earth's crust at concentrations averaging $0.09 \mathrm{mg} / \mathrm{kg}$ [2]. Selenium has six major stable isotopes have been reported and the most abundant in nature are 80Se (49.6\%) and 78Se (23.8\%) [3]. In general, selenium is present in the environment in elemental form or in the form of selenide $\left(\mathrm{Se}^{2-}\right)$, selenate $\left(\mathrm{SeO}_{4}{ }^{2-}\right)$, or selenite $\left(\mathrm{SeO}_{3}{ }^{2-}\right)$. The identity and amounts of the various oxidation-state species in soils depends enormously on the redox-potential conditions. The lower oxidation states predominate in anaerobic conditions, acidic soils, and the higher oxidation states are favored in alkaline and aerobic conditions. Both selenites and selenates are taken up by plants and converted to protein-bound selenocysteine and selenomethionine, soluble inorganic forms, several free amino acids, and volatile organoselenium compounds. The elemental form of selenium, selenium dioxide, and volatile organoselenium compounds produced by industries and plants are incorporated in the environment. Selenium occurs naturally in water in trace amounts as a result of geochemical processes, such as weathering of rocks and erosion of soils, and is usually present in water as selenate or selenite; however the elemental form may be carried in suspension [4].

Interest in selenium and health was focused primarily on the potentially toxic effects of high intakes in humans, stimulated by reports of alkali disease in livestock raised in seleniferous areas, in the last century [5]. Selenium is a trace mineral that is essential to good health but required only small amounts [6,7]. Selenium is considered as essential human micronutrient and is incorporated into proteins to make selenoproteins. Selenium is present in the selenoproteins, as the aminoacid selenocysteine (Se-Cys) [8-12].

Dietary levels of the desired amount of Se are in a very narrow range: consumption of foods containing less than $0.1 \mathrm{mg} \mathrm{kg}-1$ of this element will result in Se deficiency, whereas dietary levels above $1 \mathrm{mg} \mathrm{kg}-1$ will lead to toxic manifestations [13]. Se status varies significantly across different populations and different ethnic groups [14-15].

Selenium enters the food chain through plants, and the amount and bioavailability of selenium in the soil typically reflects the plant level. Selenium is provided by the diet in humans, but may also be provided from drinking water, environmental pollution, and in recent years through supplementation [16,17]. Plants convert Se mainly into selenomethionine (Se-Met) and incorporated it into protein place of methionine. More than $50 \%$ of the total Se content of the plant exist as Se-Met, the rest exist as selenocysteine (Se-Cys), methyl-Se-Cys and cglutamyl-Se-methyl-Cys. The later compounds are not significantly incorporated into plant protein. Higher animals are unable to synthesize Se-Met and only Se-Cys was detected in rats supplemented with Se as selenite [18]. Animals that eat grains (Brazil nuts, sunflower seeds, walnuts and grains) that were grown in selenium rich soil have higher levels of selenium in their muscles, liver, kidney, heart, spleen and fingernails. Other natural selenium sources are butter, eggs, brewer's yeast, wheat germ, garlic, raspberry leaf, radish, horseradish, onions, shellfish, broccoli, fennel seed and ginseng, among other sources.

Most ingested forms of selenium ultimately are metabolized to low molecular weight inorganic and organic compounds that play a central role in human health either via incorporation into selenoproteins or binding to selenium binding proteins [19]. Therefore, a 
tremendous effort has been directed toward the synthesis of stable organoselenium compounds that could be used as antioxidants, enzyme modulators, antitumor, antimicrobials, antihypertensive agents, antivirals and cytokine inducers. Several excellent books and reviews appeared in literature describing the biological function of organoselenium compounds [20-22].

The role of organoselenium compounds as antioxidants, as enzyme modulators, photo-chymotherapeutic agents, cytokine inducers and immunomodulators, and antihypertensive and cardiotonic agents have been recently described in literature [23].

The essentiality of selenium results as a necessary component of the active center of a number of selenoenzymes. Selenium functions as a redox center. The term selenoprotein is any protein that includes in its primary sequence of amino acids, the selenocysteine (Se-Cys) residue [24]. There are at least 30 selenoproteins that have been identified in mammals, and it has been estimated that humans have about 25 selenoproteins, including glutathione peroxidase, thioredoxin reductase, iodothyronine, deiodinase, and selenoproteins $\mathrm{P}, \mathrm{W}$, and $\mathrm{R}$ [25-27]. GPx accounts for $10-30 \%$ of plasma selenium, and selenoprotein P accounts for another $50 \%$ [28]. These enzymes protect cells from free radical damage and regulate DNA transcription and cell proliferation. The glutathione and thioredoxin systems in particular have long been considered the major pathways through which selenium exerts its potential chemopreventive effect [24], while some investigations have also suggested growth inhibitory, proapoptotic activity for selenometabolites in premalignant cells [29]. Selenium is also involved in thyroid function, T cell immunity, and spermatogenesis [28], and is a competitive antagonist of potentially carcinogenic heavy metals such as arsenic and cadmium [30].

The organism has several biological defense mechanisms against intracellular oxidative stress such as superoxide dismutase, catalase, glutathione peroxidase and nonenzymatic antioxidants such as glutathione, vitamins A, C and E, riboflavin, a B vitamin and selenium can also contribute to overcome oxidative stress [31].

Vitamin $\mathrm{E}$ is a fat-soluble vitamin known for its antioxidant capacity that is why it is well known as a lipophilic antioxidant that protects membranes from being oxidatively damaged as an electron donor to free radicals [32]. Vitamin E belongs to a group of the eight naturally occurring vitamer forms, four tocopherols $(\alpha, \beta, \gamma, \delta)$ and four tocotrienols $(\alpha, \beta, \gamma, \delta)$ based on the hydroxyl and methyl substitution in their phenolic rings, all of which have saturated and three double bonds in their phytyl tails. $\alpha$-tocopherol (from the Greek tokos $=$ child, phero $=$ to bear and ol indicating that the substance is an alcohol, is the most abundant form in nature; it's the most active and corrects human E deficiency symptoms [33]. The most abundant sources of vitamin $\mathrm{E}$ are vegetable oils, which typically contain all four tocopherol $(\alpha, \beta, \gamma, \delta)$ in varying proportions, Other important source are nuts and seeds such as sunflower and amaranth seeds.

It is well known that all forms of vitamin E are lipid soluble they easily absorbed from the intestinal lumen after dietary intake via micelles created by biliary and pancreatic secretions [34-35]. Vitamin E is then incorporated into chylomicrons and secreted into the circulation where, transported by various lipoproteins, it travels to the liver [36]. Plasma $\alpha$-tocopherol 
concentrations in humans range from 11 to $37 \mu \mathrm{mol} / \mathrm{L}$, whereas $\gamma$-tocopherol are between 2 and $5 \mu \mathrm{mol} / \mathrm{L}$. The liver plays a central role in regulating $\alpha$-tocopherol levels by directly acting on the distribution, metabolism, and excretion of this vitamin [37]. The major hepatic regulatory mechanism is the $\alpha$-tocopherol transfer protein, $\alpha$-TTP, which has been identified in a variety of mammals, including humans [38]. This protein facilitates secretion of $\alpha$-tocopherol from the liver into the bloodstream, by acquiring it from endosomes and then delivering it to the plasma membrane where it is released and promptly associates with the different nascent lipoproteins [39]. Plasma concentration of vitamin E depends completely on the absorption, tissue delivery, and excretion rate. The estimated $\alpha$-tocopherol half-life in plasma of healthy individuals is $\sim 48$ to $60 \mathrm{H}$, which is much longer than the half-life of $\gamma$ tocopherol approximately $15 \mathrm{H}$. These kinetic data underscore an interesting concept that while $\alpha$-tocopherol levels are maintained, the other forms of vitamin E are removed much more rapidly [40].

\section{Selenium and Health}

Selenium deficiency is associated with the pathogenesis of wide variety of processes that affects our health and disease including the antioxidant activity, depression, allergies, preventing oxidative stress, HIV infection, in the brain, thyroid metabolism, cancer, diabetes mellitus, male fertility, asthma, cardiovascular disorders, rheumatoid arthritis, pre-eclampsia, in immune function, in alleviate bone impairments, aging, gastrointestinal problems, selenium interactions and toxicity, anti-inflammatory effects, and hypertension. The list of clinical disorders expected to be influenced by Se deficiency is rapidly growing with time. Some selected issues regarding the role of Se in health and disease have been briefly outlined as follows:

\subsection{Se and antioxidant activity}

Selenocysteine is recognized as the 21st amino acid, and it forms a predominant residue of selenoproteins and selenoenzymes in biological tissues. The molecular structure of selenocystiene is an analogue of cysteine where a sulphur atom is replaced by Se. Even though Se and sulphur share some similar chemical properties, there are also some differences. The R$\mathrm{SeH}$ with a pKa 5.2 is more is more acidic than $\mathrm{R}-\mathrm{SH}$ with a pKa 8.5, and readily dissociated at physiological $\mathrm{pH}$, which may contribute to its biological reactivity. In the body, both organic [selenocysteine(SeCys) and selenomethionine (SeMet)] and inorganic (selenite, selenate) Se compounds are readily metabolized to various forms of Se metabolites [41]. Of particular importance during this metabolic process is the formation of hydrogen selenide $\left(\mathrm{H}_{2} \mathrm{Se}\right)$ from selenite after the action of glutathione-coupled reactions via selenodiglutathione (GS-Se-SG) and glutathione selenopersulfide (GS-SeH). $\mathrm{H}_{2} \mathrm{Se}$ is further metabolized and involved in the formation of methylselenol and dimethylselenide, which are exhaled or secreted via the skin. Selenium is also excreted in urine as trimethylselenonium ion and selenosugar compounds [42]. The selenoproteins are classified on the basis of their biological function [25]. The first identified selenoprotein was glutathione peroxidase 1 (GPx1). The 
selenoenzymes with strong antioxidant activity are GPx, GPx1, GPx3, GPx4, GPx5 and GPx6. In Humans GPx1 through GPx4 and GPx6 are selenocysteine containing enzymes. These GPx play a significant role in protecting cells against oxidative damage from reactive oxygen species (ROS) and reactive nitrogen species (RNS), which include superoxide, hydrogen peroxide, hydroxyl radicals, nitric oxide and peroxynitrite [43-44]. The other essential antioxidant selenoenzymes are the thioredoxin reductase (TrxR) where they use thioredoxin (Trx) as a substrate to maintain a $\operatorname{Tr} x / \operatorname{Tr} x \mathrm{R}$ system in a reduced state for removal of harmful hydrogen peroxide and there are three types of TrxR. Iodothyronine deiodinase (DIO) have three subtypes, DIO 1, 2, and 3 [45].

\subsection{Se and depression}

In [46] selenium's function as an antioxidant, and as a constituent of selenoproteins that are important in redox homeostasis, warrants further investigation as a risk factor for depression, and suggest a potentially novel modifiable factor in the primary prevention and management of depression. Depression is becoming recognized as an inflammatory disorder, accompanied by an accumulation of highly reactive oxygen species that overwhelm usual defensive physiological processes [47-51]. Several indicators support a role for selenium in normal brain function. During times of selenium deficiency, there is preferential storage of selenium in the brain [52]. Selenium has significant modulatory effects on dopamine [53] and dopamine plays a role in the pathophysiology of depression and other psychiatric illnesses [54]. Diminished levels of selenium in the brain are associated with cognitive decline [55] and Alzheimer's disease [56]. Selenium supplementation has been linked with improvements in mood [57] and protection against postpartum depression [58]. What is unclear is if low dietary selenium is a risk factor for the development of depression. In recognition of selenium's biological activity, it has been hypothesized that low levels of dietary selenium would be associated with an increased risk of major depressive disorder (MDD) in a representative population-based sample of women.

Alterations in redox biology are established in depression; however, there are no prospective epidemiological data on redox-active selenium in depression. It is known that selenium's function as an antioxidant, and as a constituent of selenoproteins that are important in redox homeostasis, warrants further investigation as a risk factor for depression, and suggest a potentially novel modifiable factor in the primary prevention and management of depression.

\subsection{Selenium and allergies}

The International Study of Asthma and Allergies in Childhood (ISAAC) found that one in four New Zealand children aged 6-7 years had experienced asthma symptoms, which placed New Zealand in the top four countries for asthma prevalence [59]. The reasons for the high prevalence and severity of this condition or the increased prevalence of asthma over the last 20 years are not well understood. One of a number of environmental factors that have been proposed as a reason for the escalation in asthma prevalence is a decreasing intake of dietary antioxidants [60]. It is well known that selenium is essential for the optimal 
functioning of the selenoenzymes glutathione peroxidases (GPx) and thioredoxin reductases, powerful antioxidants, and is found abundantly in lung tissue and the extracellular fluid of the respiratory system [61]. Selenium has been implicated in inflammation by reducing the severity of the inflammatory response through modulation of the pro-inflammatory leukotrienes, important mediators of acute asthmatic reactions as well as sustaining the inflammatory process causing a late allergic reaction metabolism [62]. Evidence from randomized controlled trials [63] and basic mechanistic work investigating the effect of selenium on markers of inflammation and oxidative stress [62]. Evidences have supported a protective role for selenium in asthma, although other studies have not [64-66]. The ISAAC study does not support a strong association between selenium status and the high incidence of asthma in New Zealand. However, there was a modest association between lower plasma selenium and whole blood glutathione peroxidase activity and higher incidence of persistent wheeze [67].

\subsection{Selenium in preventing oxidative stress}

The reactivity of organoselenium compounds $[22,68]$ characterized by high nucleophilicity and antioxidant potential, and provides the basis for their pharmacological activities in mammalian models. Organochalcogens have been widely studied given their antioxidant activity, which confers neuroprotection, antiulcer, and antidiabetic properties. Given the complexity of mammalian models, understanding the cellular and molecular effects of organochalcogens has been hampered. In reference [69] the nematode worm Caenorhabditis elegans is an alternative experimental model that affords easy genetic manipulations, green fluorescent protein tagging, and in vivo live analysis of toxicity. Manganese (Mn)-exposed worms exhibit oxidative-stress-induced neurodegeneration and life-span reduction. Diethyl-2-phenyl-2-tellurophenyl vinyl phosphonate (DPTVP) and 2-Phenyl-1,2-benzoisoselenazol-3- $(2 \mathrm{H})$-one (Ebselen) were tested for reversing the Mn-induced reduction in survival and lifespan in this nematode. DPTVP was the most efficacious compound as compared to Ebselen in reversing the Mn-induced toxicity and increasing in survival and life span. DPTVP and ebselen act as antiaging agents in a model of Mn-induced toxicity and aging by regulating DAF-16/FOXO signaling and attenuating oxidative stress.

Bone is a specialized connective tissue, which forms the framework of the body. Various physiological conditions can adversely affect femoral bone metabolism. These physiological conditions could be food deprivation [70], and iodine and/or selenium (Se) deficiency [71,72] and antithyroid drugs [73] affects bone maturation. Selenium is an important protective element that may be used as a dietary supplement protecting against oxidative stress, cellular damage and bone impairments [74].

\subsection{Selenium in HIV infection}

The HIV pandemic has placed a great demand upon the scientific community to develop effective prevention and treatment methods. Since the beginning of the pandemic in 1981, over 25 million people are estimated to have died from the disease [75]. It is currently a leading cause of death in many parts of the world, and a disease that disproportionately affects 
the marginalized and socially disadvantaged. It is currently a leading cause of death in many parts of the world, and a disease that disproportionately affects the marginalized and socially disadvantaged. Many of those affected also suffer from chronic food insecurity and malnutrition, so therapies that could potentially target both HIV disease and malnutrition, such as multivitamins, have been extensively researched for potential benefits [76]. Among such therapies, the antioxidant micronutrients theorized to have potential benefits in HIV disease, apart from correcting deficiencies, have been examined frequently $[77,78]$.

Selenium has an inhibitory effect on HIV in vitro through antioxidant effects of glutathione peroxidase and other selenoproteins. Numerous studies have reported low selenium status in HIV-infected individuals, and serum selenium concentration declines with disease progression. Some cohort studies have shown an association between selenium deficiency and progression to AIDS or mortality. In several randomized controlled trials, selenium supplementation has reduced hospitalizations and diarrheal morbidity, and improved CD4+ cell counts, but the evidence remains mixed. Additional trials are recommended to study the effect of selenium supplementation on opportunistic infections, and other HIV disease-related comorbidities in the context of highly active antiretroviral therapy in both developing and developed countries [79].

There is a historical record showing that organoselenium compounds can be used as antiviral and antibacterial agents. This topic has been reviewed by [22,23].

\subsection{Selenium in the brain}

In addition to the well-documented functions of Se as an antioxidant and in the regulation of the thyroid and immune function [80]. Recent advances have indicated a role of Se in the maintenance of brain function [81]. Selenium is widely distributed throughout the body, but is particularly well maintained in the brain, even upon prolonged dietary Se deficiency [82]. In the brain, the highest concentration of Se is found in the gray matter, an area responsible for chemical synaptic communication [83]. It has been shown that rats on a Se-deficient diet for thirteen weeks retained Se in their brain, while their plasma Se concentrations were depleted [84]. After intraperitoneal injection of ${ }^{75} \mathrm{SeO}^{2-}$ into Se-deficient rats, the brain rapidly sequesters a large portion of the available Se [85]. In the brain, it was found that the cerebellum accumulated the highest concentration of Se, followed by the cortex, medulla oblongata, cerebral hemisphere, and the spinal cord. Interestingly, Se retention in the brain depends on Selenoprotein P expression [86]. Because the body preferentially allocates available Se to the brain during Se deficiency, Se may play an essential role in the brain. More evidence for the brain being at the apex of Se retention is provided by a study showing that a six generation Se deficiency in rats caused a more than $99 \%$ reduction of Se concentration in the liver, blood, skeletal tissue, and muscle, while the brain retained a $60 \%$ of the Se [87]. Se concentration in Alzheimer's brains was found to be $60 \%$ of the age-matched control individuals [88]. Accumulated lines of evidence indicate important roles of selenoproteins in the maintenance of optimal brain functions via redox regulation. Decreased expression of several selenoproteins is associated with the pathologies of a few age-associated neurodisorders, including Parkinson's disease, Alzheimer's disease and epilepsy [81]. 
Oxidative stress and generation of reactive oxygen species are strongly implicated in a number of neuronal and neuromuscular disorders, including epilepsy. The functions of selenium as an antioxidant trace element are believed to be carried out by selenoproteins that possess antioxidant activities and the ability to promote neuronal cell survival [89]. It is known the role of selenium in a detoxifying enzyme, glutathione peroxidase, this element has been demonstrated to have a positive biological function in various aspects of human health [90]. Oxidative stress and generation of reactive oxygen species are strongly implicated in a number of neurologic disorders including seizure disorders. Oxidative phosphorylation occurring in the mitochondria produces oxygen radicals routinely in all tissues as well as the nervous system. One important defense may be to remove the oxygen radicals. Seleniumrequiring processes are involved in normal maintenance of cell function. However, when the system is overused or chronically activated beyond its normal state, such as recurrent or intractable seizures, abnormal increases in by-products can produce neuronal cell damage. Selenium provides protection from reactive oxygen species-induced cell damage. The proposed mechanisms are mainly through the functions of seleno-dependent enzymes and selenoproteins [82,91]. It seems that selenium plays an important role in stopping the vicious cycle of oxidative stress and neuronal damage in patients with intractable seizures by restoring the defense mechanism.

\subsection{Selenium and the thyroid}

Some selenoproteins of the human selenoproteome display multiple genes performing similar functions. The main selenoprotein families are the glutathione peroxidases (GPxs; seven genes), the thioredoxin reductases (TRxs; three genes) and the iodothyronine deiodinases (DIs; three genes) [92,93]. The GPxs, which possess oxidoreductase functions, protect the cell from oxidative stress. The TRxs form a cellular redox system, existing in many organisms, which is essential for cell development and proliferation. The DIs that catalyzes the conversion of T4 to T3 provides the sources of T3 production. It may thus be hypothesized that the essential micronutrient selenium, in the form of Se-Cys, modulates redox-sensitive signaling pathways and thereby potentially modifies selenoprotein gene expression. These findings have aroused growing interest of the scientific community in this multifaceted element. In this context, whereas selenium administration for cancer chemoprevention produced questionable results, those of selenium supplementation in patients with autoimmune thyroid disease have been more encouraging. In [94] comprises an in-depth discussion of the link between selenium and thyroid function; it provides a critical analysis of the data contained in recent studies, an update and evaluation of current knowledge with regard to the mechanisms of action of selenium, and reflections on the prospects for selenium supplementation in thyroid pathology.

Evidence in support of selenium supplementation in thyroid autoimmune disease is evaluated; the results herein presented demonstrating the potential effectiveness of selenium in reducing the antithyroid peroxidase titer and improving the echostructure in the ultrasound examination. However, considerable discord remains as to who should comprise target groups for selenium treatment, who will most benefit from such treatment, the precise im- 
pact of the basal antithyroid peroxidase level, and the effect of disease duration on the treatment outcome. Clearly, further in-depth studies and evaluation are required concerning the mechanism of action of selenium as well as the choice of supplements or dietary intake.

\subsection{Selenium in cancer}

The reactive oxygen species (ROS) are derived from cellular oxygen metabolism and from exogenous sources. An excess of ROS results in oxidative stress and may eventually cause cell death. ROS levels within cells and in extracellular body fluids are controlled by concerted action of enzymatic and non-enzymatic antioxidants. The essential trace element selenium exerts its antioxidant function mainly in the form of selenocysteine residues as an integral constituent of ROS-detoxifying selenoenzymes such as glutathione peroxidases $(\mathrm{GPx})$, thioredoxin reductases (TrxR) and possibly selenoprotein $\mathrm{P}(\mathrm{SeP})$. In particular, the dual role of selenoprotein $\mathrm{P}$ as selenium transporter and antioxidant enzyme is highlighted herein. A cytoprotective effect of selenium supplementation has been demonstrated for various cell types including neurons and astrocytes as well as endothelial cells. Maintenance of full GPx and TrxR activity by adequate dietary selenium supply has been proposed to be useful for the prevention of several cardiovascular and neurological disorders. On the other hand, selenium supplementation at supranutritional levels has been utilized for cancer prevention: antioxidant selenoenzymes as well as prooxidant effects of selenocompounds on tumor cells are thought to be involved in the anti-carcinogenic action of selenium $[95,96]$.

Among various antioxidant minerals, selenium it may prove to be of major significance as a prophylactic agent against cancer. Low blood selenium concentration and incidence of carcinogenesis have been well observed in both animals [97] as well as in human studies [98]. In addition, it has been demonstrated in a double blind randomized cancer prevention trial in humans that increased selenium intake has a significant role in the treatment of cancer [99]. A similar prospective study could also be designed for other cancers to determine the chemopreventive effect of Se. Selenium has also been reported to have a beneficial effect on the incidence of gastrointestinal and bladder cancers [100,101].

Although selenium is reported to play a significant role in cancer development, its exact anticancer mechanism of action at molecular levels is not fully understood. However, it has been hypothesized that the most possible mechanistic action of Se as chemoprevention is its role in the antioxidant defense systems to reduce oxidative stress and limit DNA damage $[24,102]$. Experiments carried out within the framework of a canine model using male beagle dogs to mimic prostate cancer in humans showed that the damage to DNA was significantly reduced when the animals were exposed to increased Se dietary supplements [103]. The effectiveness of Se in the prevention of DNA damage, however, depends on its chemical forms. In an in vitro study [104] found that selenocysteine inhibited DNA damage more strongly than the selenomethionine. Other possible anticancer mechanisms of Se include the induction of apoptosis, cell-cycle arrest and DNA-repair genes, inhibition of protein kinase $C$ activity and cell growth and effect on estrogen- and androgen-receptor expression [102].

In [105] knowledge of the plasma selenium levels are associated with optimized concentration or activity of specific selenoproteins can provide considerable insights from epidemio- 
logical data on the possible involvement of those selenoproteins in health, most notably with respect to cancer. For cohort studies, if selenoproteins such as glutathione peroxidase and selenoprotein $\mathrm{P}$ are relevant to cancer, one might only expect to see an effect on risk when the concentrations in the cohort range from below, to above, the level needed to optimize the activity or concentration of these enzymes. Similarly, trials would only show a beneficial effect of supplementation if selenium status were raised from below, to above, the optimal concentration for the selenoproteins likely to be implicated in cancer risk, as occurred in the Nutritional Prevention of Cancer (NPC) trial but not in Selenium and Vitamin E Cancer Prevention Trial (SELECT). The most powerful evidence for the involvement of selenoproteins in human health comes from epidemiological studies that have related single nucleotide polymorphisms in selenoproteins to disease risk. The totality of the evidence currently implicates GPx1, GPx4, SEPS1, Sep15, SEPP1 and TXNRD1 in conditions such as cardiovascular disease, pre-eclampsia and cancer. Future studies therefore need to determine not only selenium status, but genotype, both in selenoproteins and related pathways, when investigating the relationship of selenium with disease risk.

\subsection{Selenium in diabetes}

The evidence supporting an effect of selenium on the risk of diabetes is variable, occasionally conflicting, and limited to very few human studies. Following a trial investigating the effect of selenium supplementation $(200 \mu \mathrm{g} /$ day $)$ on skin cancer, subsequent analysis showed that there was an increased risk of developing type 2 diabetes in the supplemented group. Evidence from analysis of NHANES III [106] supports these findings; the adjusted mean serum selenium concentrations were slightly, but significantly, higher in diabetics compared with those without the disease. This study, conducted in an elderly French population, found a sex-specific protective effect of higher selenium status at baseline on later occurrence of dysglycemia; that is, risk of dysglycemia was significantly lower in men with plasma selenium, but no significant relationship was observed in women [107].

The role of selenium as an antioxidant, particularly within the GPxs, selenium is likely to be important in reducing oxidative stress, an important risk factor for developing diabetes. There are also plausible suggestions that selenium can influence glucose metabolism. However, at high intakes it is also conceivable that reactive oxygen species could be generated or selenium may accumulate in the organs associated with glucose metabolism [108]. In patients with diabetes, selenium supplementation $(960 \mu \mathrm{g} /$ day) reduced NF- $\kappa B$ levels to those comparable with nondiabetic controls [109]. In addition, further analysis of the Nutritional Prevention of Cancer trial data has shown an increased risk of self-reported Type-2 diabetes in those supplemented with Se, though the effect was significant only in those in the top tertile of plasma Se at baseline [110].

\subsection{Selenium and male fertility}

Selenoprotein P transports selenium particularly to testis and brain [111]. Among the five enzymes of GPx, GPx1 prevents apoptosis induced by oxidative stress and GPx4 acts directly on membrane phospholipid hydroperoxides and detoxifies them. Selenium as GPx, is 
present in spermatids and forms the structural part in the mid piece of mature spermatozoa. Some well known effects of selenium deficiency include instability of the middle piece leading to defective sperm motility [112], low reproductive ability and abnormal development of spermatozoa [113]. Selenium is also required for testosterone synthesis and sequential development of flagella [114]. It can restore the physiological constitution of polyunsaturated fatty acid in the cell membrane [115]. Testes are extremely resistant to Se depletion and have high Se content. Recent studies have shown that sperm and testicular Se was unaffected by the supplementation, suggesting that testes are protected from Se excess as well as from Se deficiency [116].

\subsection{Selenium in asthma}

Se status is decreased in patients with asthma, as is activity of glutathione peroxidase in platelets and erythrocytes. There is an associated marked oxidant/antioxidant imbalance in the blood of asthmatics, which reflects poor antioxidant status and enhanced inflammatory mediated oxidative stress [117]. According to the University of Maryland Medical Center, a 2004 study of 24 asthmatics that were given selenium supplements for 14 weeks had significant improvement in their symptoms when compared to a control group given a placebo. Although this is a small study done over a short amount of time, it's encouraging [118].

\subsection{Selenium in cardiovascular disorders}

Free radicals are toxic to the myocardium and can cause tissue damage that leads to extensive necrosis, myocytolysis and cellular edema [119]. Atherosclerotic plaque formation may be a reflection of sub-optimal GPx4 activity in the prevention of LDL oxidation, with subsequent uptake by endothelial cells and macrophages in arterial blood vessels [120]. Selenium via GPx reduces phospholipids, hydro peroxides and cholestryl esters associated with lipoproteins and may therefore, not only reduce the accumulation of oxidized LDL in arterial wall but also reduce platelet aggregation and activation of monocyte and macrophages [121]. Selenium owing to its antithrombotic effect on the interaction between platelets and endothelial cells via GPx, also provides concrete evidence in the prevention of atherosclerosis [122].

The study on acute myocardial infarction (AMI) patients, it was observed that selenium dependent GPx level decreases significantly in AMI patients and explained it as an imperative consequent of GPx activity in annihilating oxygen toxicity by metabolizing $\mathrm{H}_{2} \mathrm{O}_{2}$ and inhibiting further free oxygen radical production in early phase of myocardial infarction [123].

\subsection{Selenium in rheumatoid arthritis}

Scientific research shows that people with rheumatoid arthritis have low levels of selenium. A study suggests, it is part of the body's defense mechanism [124]. In reference [125] the authors found lower selenium levels in patients with rheumatoid arthritis who were treated with arthritis medication compared with people without the condition. In people without 
rheumatoid arthritis or a family history of the condition, low levels of the mineral may increase the risk of developing rheumatoid arthritis [126].

\subsection{Selenium in pre-eclampsia}

In reference [124], pre-eclampsia (pregnancy induced hypertension; $\mathrm{PIH}$ ), is an important cause of maternal morbidity and mortality with essentially unknown etiology. However, the precise factors involved in the pathogenesis of PIH are still unknown [127]. It has been conceived that free radical mediated oxidative stress may contribute to the development of preeclampsia. Selenium and its related enzymes especially GPx play a crucial role in annihilating oxygen toxicity and there by controlling the progression of disease [128]. In addition, selenium deficiency in women may result in infertility, miscarriages and retention of the placenta [129].

\subsection{Selenium in immunity}

In reference [130], the generation of ROS in a limited dose is one of the processes induced by the immune system to destroy microbial pathogens and viruses. However, the over-production of ROS can also cause damage to the host cells that need to be protected by Se at various stages in the immune system. Keshan disease, an endemic cardiomyopathy in China that develops as a result of Se deficiency, may also be complicated with viral infection, and this has led to the investigation of the effects of viruses, such as coxsackievirus, on Se-deficient animals [131,132]. Results from animal studies have demonstrated that Se deficiency can lead to an impairment of immune functions that result in the inability of phagocytic neutrophils and macrophages to destroy antigens. A low Se status in humans has been reported to cause a decreased immune response to poliovirus vaccination [133]. This study also demonstrated that the subjects supplemented with Se showed fewer mutations in poliovirus than those who received a placebo. The involvement of Se in the immune system may be associated with a number of mechanisms, including the increased activity of natural killer (NK) cells, the proliferation of T-lymphocytes, increased production of interferon c, increased high-affinity interleukin-2 receptors, stimulation of vaccine-induced immunity and increased antibody-producing B-cell numbers [134,135].

\subsection{Selenium in bone impairments}

Osteoblasts (bone-forming cells) and osteoclasts (bone-resorption cells) are involved in bone remodeling. Therefore, any loss of osteoblastic activity or an increase in osteoclastic activity could lead to a decrease in bone-mineral densities (BMD), bone mass, and make the bones more likely to osteoporosis, and ultimately to fractures [136]. In addition, high levels of reactive oxygen species (ROS) and many other factors such as genetic race, hormonal, mechanical, and nutritional statues are involved in bone weakness and fractures. ROS shift cells into a state of oxidative stress [137] which contributes to the etiology of various degenerative diseases that cause tissue injury $[136,137]$. Studies have demonstrated that the ischemia-reperfusion processes that occur after a fracture are associated with oxidative stress development $[136,138]$. It is believed that bone markers such as osteocalcin and alkaline phosphatase as 
well as antioxidant enzymes play a significant role in fracture healing. However, to the best of our knowledge, there are no reports about the use of vitamins A, C, E, and selenium as antioxidant therapy to explore their effects in the levels of bone-healing markers and oxidative stress parameters of osteoporotic patients. In [139] suggests that selenium is an important protective element that may be used as a dietary supplement protecting against bone impairments.

\section{Vitamin E and Health}

\subsection{Vitamin E}

All forms of vitamin E meet the chemical definition of an antioxidant moiety: "chain-breaking free radical scavenger." Indeed consistent data have shown that all isoforms act as potent antioxidants in conventional in vitro paradigms. The free hydroxyl group on the aromatic ring is thought to be responsible for this property, and a relatively stable form of the original vitamin $\mathrm{E}$ is formed when hydrogen from this group is donated to a free radical. Yet, definitive proof that vitamin E possesses antioxidant properties has been hampered for a long time because of a lack of sensitive and specific analytical techniques to measure this biologic event in vivo [36]. Apart from antioxidant properties, more recent studies have clearly demonstrated that vitamin E also possesses important non-antioxidant cellular and molecular functions. One of the first roles of $\alpha$-tocopherol in cell signaling was the report that it inhibits smooth muscle cell proliferation, decrease protein kinase C activity, and controls expression of the $\alpha$-tropomyosin gene [140].

One of the major vitamin E-deficiency symptoms are neurological disorders. Furthermore, vitamin E deficiency is related to female infertility. The frame to pinpoint the physiological action of vitamin $\mathrm{E}$ is set by its chemical nature: (i) It is a redox-active compound prone to undergo 1- and 2-electron transitions and (ii) it is highly lipophilic, although this property may be modulated by phosphorylation [141]. In [142] oxidative stress is a developing research field and is being examined in female infertility. Prooxidants, also called free radicals or reactive oxygen species (ROS), and their neutralizing agents the antioxidants are the main chemicals of the oxidation mechanism. The term oxidative stress refers to the dysequilibrium between the free radicals and the antioxidants in favor of the free radicals. In actuality, free radicals are not so frightening, since they are necessary for the adequate reproductive functions within the ovary and the endometrium. Vit E administration may improve the endometrial response in unexplained infertile women via the likely antioxidant and the anticoagulant effects. It may also modulate the antiestrogenic effect of clomiphene citrate and the problem of a thin endometrium in these cycles may be adjusted.

Some non-antioxidant properties of vitamin E could play a key role in neuroprotection. It has been recently shown that $\alpha$-tocotrienol, at nanomolar concentrations, protects mouse hippocampal and cortical neurons from cell death by modulating neurodegenerative signaling cascades. Furthermore, it has been shown that $\alpha$-tocotrienol modulates 12-lipoxygenase and phospholipase A2 activities, which are implicated in glutamate-induced neuronal cell 
death [143]. Some vitamin E forms ( $\alpha$ - and $\gamma$-tocopherol, tocotrienols) also exhibit potent anti-inflammatory properties $[144,145]$. The introduction of the free radical theory of brain aging has propelled a renewed interest in this vitamin. As result, by preventing and/or minimizing the oxidative stress dependent brain damage, this vitamin plays important role in brain aging, cognition, and Alzheimer's dementia.

Vitamin E is a potent peroxyl radical scavenger that prevents lipid peroxidation [146] and is found in high concentrations in immune cells [147]. Deficiency in vitamin E is associated with increased oxidative stress [148] and impaired immune function, including both humoral and cell-mediated immunity, phagocyte function, and lymphocyte proliferation [149]. Age-related declines in immune function can be restored by vitamin E supplementation [150]. This vitamin is an exogenous, lipidsoluble antioxidant molecule. It is thought to be a direct free radical scavenger by activating the intracellular antioxidant enzymes and saving the cell membranes from lipid peroxidation, which was demonstrated on sperm membrane components [151]. Its antioxidant effect was concluded in cancer therapy, high-risk pregnancy and male infertility [152-154].

Vitamin E ( $\alpha$-tocopherol acetate) is found within the phospholipid bilayer of cell membranes where it functions as an electron donor to free radicals. It has been recognized as one of the body's major natural antioxidants. Another antioxidant, Se appears to function as an antimutagenic agent, preventing the malignant transformation of normal cells. Its protective effects seem to be primarily associated with its presence in the seleno-enzymes which are known to protect DNA and other cellular components from oxidative damage [44].

Selenium, vitamin A (retinol) and vitamin E ( $\alpha$-tocopherol) are essential micronutrients for human health. Both selenium and vitamin $\mathrm{E}$ are important in host antioxidant defense and immune function. It has been reported that deficiency of selenium and vitamins may promote peroxidation events leading to the release of free radicals. All have free-radical-scavenging properties that allow them to function as physiologic antioxidants in protecting a number of chronic diseases, such as cancer and cardiovascular disease. In addition to its antioxidant capacity, $\alpha$-tocopherol regulates expression of genes involved in a wide range of cell functions, including cell cycle regulation, inflammation and cell adhesion, cell signaling, and lipid uptake [155].

Selenium also has an important role in antioxidant defense and immune function. Due to its incorporation as selenocysteine into glutathione peroxidase (GPX) [156] and thioredoxin reductase [157], selenium is important for the control of oxidative stress and, therefore, the redox tone of the cell. In total, there are 25 identified selenoproteins ( 24 in rodents), many with unknown function [25]. Selenium is important for cytotoxic T-lymphocyte and natural killer cell activity [158], respiratory burst [159], and protection against endotoxin-induced oxidative stress [160]. Multiple studies have shown that NF-kB activation can be affected by selenium status [161,162], and selenium deficiency can alter chemokine and cytokine expression during viral infections [163]. Various investigators have reported the role of selenium as an inhibitor of carcinogenesis in various organs including liver, skin, stomach, mammary gland, gastrointestinal and oral cavity $[164,165]$. 
In [166] blader cancer represents an important cause of morbidity and mortality. In 2010 it was again the second most common genitourinary cancer in the United States with an established 70,530 new cases and 14,680 deaths [167]. Currently it is estimated that more than 500,000 men and women in the United States have a history of bladder cancer. The etiology of most bladder urothelial carcinoma is associated with tobacco exposure, occupational exposure to aromatic amines, and exposure to the chemical and rubber industries [168]. Bladder cancer is the most expensive cancer in the United States, accounting for almost \$3.7 billion (2001 value) in direct costs [169]. There is substantial epidemiological and biological evidence that selenium and vitamin E may prevent bladder cancer. A recent meta-analysis of 7 published epidemiological studies, including 3 case-control, 3 nested case-control and 1 case cohort series, examined the association between selenium levels and bladder cancer [170]. In the analysis stratified by gender only women showed a significantly decreased risk associated with selenium. An opposite gender pattern, with protective effects in men but not in women, was reported in a meta-analysis of selenium supplementation, primary cancer incidence and mortality [171]. Epidemiological and biological evidence suggests a preventive effect of selenium and vitamin E on bladder cancer. These researches assessed the effect of selenium and/or vitamin E on bladder cancer development.

\subsection{Selenium and vitamin $\mathrm{E}$}

Selenium and vitamin E are essential components of the human diet and have been studied as antioxidants and/or potential agents for a variety of human diseases. Various formulations of both selenium and vitamin $\mathrm{E}$ have been shown to possess a therapeutic and preventive effect against prostate cancer. The Selenium and Vitamin E Cancer prevention Trial (SELECT) started in 2001 and was a phase III, randomized placebo/controlled human trial to investigate the prostate cancer chemopreventive effects of selenium and vitamin $\mathrm{E}$ or their combination [172,173].

Sselenium an essential trace element, and vitamin E, a lipid soluble antioxidant, are important mediators for protection against oxidative stress. Deficiencies in either Se or vitamin E result in increased viral pathogenicity and altered immune responses. Furthermore, deficiencies in either Se or vitamin E results in specific viral mutations, changing relatively benign viruses into virulent ones. Thus, host nutritional status should be considered a driving force for the emergence of new viral strains or newly pathogenic strains of known viruses [174].

Several studies have evaluated the possible association between antioxidants vitamins or selenium supplement and the risk of prostate cancer, but the evidence is still inconsistent. We systematically searched PubMed, EMBASE, the Cochrane Library, Science Citation Index Expanded, Chinese biomedicine literature database, and bibliographies of retrieved articles up to January 2009. We included 9 randomized controlled trials with 165,056 participants; methodological quality of included trials was generally high. Meta-analysis showed that no significant effects of supplementation with $\beta$-carotene ( 3 trials), vitamin $C$ ( 2 trials), vitamin E ( 5 trials), and selenium ( 2 trials)versus placebo on prostate cancer incidence. The mortality of prostate cancer did not differ significantly by supplement of $\beta$-carotene ( 1 trial), vitamin 
C (1 trial), vitamin E (2 trials), and selenium (1 trial). This study indicates that antioxidant vitamins and selenium supplement did not reduce the incidence and mortality of prostate cancer; these data provide no support for the use of these supplements for the prevention of prostate cancer [175].

Epidemiological studies demonstrated that human exposure to methylmercury (MeHg) may contribute to the development and progression of metabolic and cardiovascular disorders. However, the mechanisms involved and the role of selenium (Se) and vitamin E (VE) supplementation in modulating $\mathrm{MeHg}$ cardiovascular toxicities remain unclear. The effects of Se and VE supplementation on MeHg-mediated systemic oxidative stress, antioxidant defense, inflammation, and endothelial dysfunction are carried out in an animal model. Male Sprague-Dawley rats were fed a starch-based casein diet or the same diet supplemented with 1 or $3 \mathrm{mg} \mathrm{Se} / \mathrm{kg}$ diet and with or without 250 or $750 \mathrm{mg} \mathrm{VE} / \mathrm{kg}$ diet. After 28 days of dietary treatment, rats were gavaged with 0 or $3 \mathrm{mg} \mathrm{MeHg} / \mathrm{kg} \mathrm{BW}$ for 14 consecutive days. Results suggested that exposure to $\mathrm{MeHg}$ may increase the risk of cardiovascular disease by decreasing circulating paraoxonase- 1 activities, increasing serum oxidized low density lipoprotein levels, and associated systemic inflammation and endothelial dysfunction as reflected by increased leukocyte counts and serum levels of intercellular adhesion molecule- 1 and monocyte chemotactic protein-1. Se and VE supplementation may either alleviate or augment the effects of $\mathrm{MeHg}$, depending on their doses and combinations [176].

The analysis of the hepatotoxic effect of malathion in adult male rats and evaluate the possible hepatoprotective effect of vitamin E and/or selenium. Oral administration of malathion for 45 days significantly induced marked hepatic injury as revealed by increased activity of the plasma enzymes (alanine aminotransferase (ALT), aspartate aminotransferase (AST), lactate dehydrogenase (LDH) and gamma-glutamyl transferase GGT). Oral administration of vitamin $\mathrm{E}$ and selenium in combination with malathion exhibited a significant protective effect by lowering the elevated plasma levels of the previous enzymes. Light microscopic investigation revealed that malathion exposure was associated with necrosis of hepatocytes, marked changes of liver tissues in the form of dilated veins, hemorrhagic spots and some degenerative signs of hepatocytes [177].

\section{Conclusion}

Research on Se during the last few years has produced a great deal of evidence demonstrating the important role that Se and its metabolites play in human diseases. In particular, our knowledge of the functional roles of the GPx and TrxR groups as essential antioxidant selenoenzymes in protecting cells from oxidative stress has greatly increased, as has the link between these enzymes and various diseases. However, there are still areas of research that require in-depth study, including the mechanistic modes of action of Se in cancer etiology, how Se delivers its anticancer activity at the molecular and genetic levels, and what biomarkers can be used to accurately measure the efficacy of Se for use in chemoprevention. It is not well understood the specific mechanism by which Se protects cells and tissue at the 
cellular level from damage due to oxidative stress; this is particularly relevant in heart diseases, which are still a major cause of death worldwide. Given the number of Se cancer preventive trials that are currently being undertaken in many countries, the significant outcomes of these trials will not only provide us with more information on optimal Se intake for the treatment and prevention of cancer, but they will also provide us with strategies in the management of other potential human diseases associated with low Se status. Until the specific biomarkers are identified that will directly link Se with disease prevention and treatment, its use as supplements in health therapy should be taken with caution.

The Selenium and Vitamin E Cancer prevention Trial (SELECT) failed to show an effect in human population. However, pre- and pro-SELECT studies are still supporting the potential usefulness of selenium and/or vitamin $\mathrm{E}$ for prevention of prostate cancer and possibly other conditions. Much remains to be understood about the absorption, metabolism and physiologic chemistry of these agents. Nonetheless, the existing evidence supporting selenium and vitamin $\mathrm{E}$ as potential prostate cancer chemopreventive agents is possibly enough to justify further efforts in this direction.

My goal in putting this review together was to provide a wide range of subjects dealing with selenium and vitamin E supplementation, that are used in chronic disease prevention, due to their antiradical activities indicating that the combine effects of Se and vitamin E could provide an important dietary source of antioxidants and/or potential agents for a variety of human diseases. It is my hope that readers will find this chapter to be useful in further studies dealing with this subject.

\section{Author details}

Manuel Soriano García*

Chemistry of Biomacromolecules Department, Chemistry Institute, National Autonomus University of México, University City, Mexico

\section{References}

[1] Berzelius, J. J. (1818). Afhandl. Fys. Kemi Minerag. 6, 42

[2] Shamberger, R. J. (1984). Selenium. In Biochemistry of the Essential Ultratrace Elements, Earl Frieden, Ed.; Plenum Press; New York, NY, 3, 201-237.

[3] Brasted, R. C. (1961). In Comprehensive Inorganic Chemistry: Sulfur. Selenium, Tellurium, Polonium and Oxygen, Robert C. Brasted, Ed.; D. Van Nostrand Co.; Princeton, NJ, 2.

[4] Merian, E. (1984). Introduction on environmental chemistry and global cycles of chromium, nickel, cobalt beryllium, arsenic, cadmium and selenium, and their derivatives. Toxicological and Environmental Chemistry, 8, 9-38. 
[5] Smith, M., Franke, K. W., \& Westfall, B. B. (1936). The selenium problem in relation to public health. A preliminary survey to determine the possibility of selenium intoxication in the rural population living in seleniferous soil. US Public Health Reports, 51, 1496-1505.

[6] Thomson, C. D. (2004). Assessment of requirements for selenium and adequacy of selenium status: a review. European Journal of Clinical Nutrition, 58, 391-402.

[7] Goldhaber, S. B. (2003). Trace element risk assessment vs toxicity. Regulatory Toxicology and Pharmacology, 38, 232-242.

[8] Castellano, S., Gladyshev, V. N., Guigo, R., \& Berry, M. J. (2008). SelenoDB 1.0: a database of selenoprotein genes, proteins and SECIS elements. Nucleic Acids Research, 36, 332D-338D.

[9] Allmang, C., Wurth, L., \& Krol, A. (2009). The selenium to selenoprotein pathway in eukaryotes: more molecular partners than anticipated. Biochemica et Biophysica Acta, 1790, 1415-1423.

[10] Arbogast, S., \& Ferreiro, A. (2009). Selenoproteins and protection against oxidative stress selenoprotein $\mathrm{N}$ as a novel player at the crossroads of redox signaling and calcium homeostasis. Antioxidants \& Redox Signaling, 12, 893-904.

[11] Kipp, A., Banning, A., Van Schothorst, E. M., Meplan, C., Schomburg, L., Evelo, C., Coort, S., Gaj, S., Keijer, J., Hesketh, J., \& Brigelius-Flohe, R. (2009). Four selenoproteins, protein biosynthesis, and Wnt signaling are particularly sensitive to limited selenium intake in mouse colon. Molecular Nutrition \& Food Research, 53, 1561-1572.

[12] Lescure, A., Rederstorff, M., Krol, A., Guicheney, P., \& Allamand, V. (2009). Selenoprotein function and muscle disease. Biochimica et Biophysica Acta, 1790, 1569-1574.

[13] Lobinski, R., Edmonds, J. S., Sukuki, K. T., \& Uden, P. C. (2000). Species-selective determination of selenium compounds in biological materials. Pure and Applied Chemistry, 72, 447-461.

[14] Bleys, J., Navas-Acien, A., Stranges, S., Menke, A., Miller, E. R., III, \& Guallar, E. (2008). Serum selenium and serum lipids in US adults. The American Journal of Clinical Nutrition, 88, 416-423.

[15] Johnson, C. C., Fordyce, F. M., \& Rayman, M. P. (2010). Symposium on "geographical and geological influences on nutrition": factors controlling the distribution of selenium in the environment and their impact on health and nutrition. Proceedings of the Nutrition Society, 69, 119-132.

[16] Navarro-Alarcon, M., \& Cabrera-Vique, C. (2008). Selenium in food and the human body: a review. Science of the Total Environment, 400, 115-141.

[17] Schrauzer, G. N., \& Surai, P. F. (2009). Selenium in human and animal nutrition: resolved and unresolved issues. A partial historical treatise in commemoration of the fiftieth anniversary of the discovery of the biologically essentiality of selenium, dedi- 
cated to the memory of Klaus Schwarz (1914-1978) on the occasion of the thirtieth anniversary of his dead. Critical Reviews in Biotechnology, 29, 2-9.

[18] World Health Organization. (1987). Selenium. Geneva; WHO.

[19] Thompson, H. J. (2001). In Selenium: Its Molecular Biology and Role in Human Health, Dolph L. Hatfield, Ed.; Kluwer Academic. Publishers; Boston, MA, 283-297.

[20] Hatfield, D. L. (2001). In Selenium: Its Molecular Biology and Role in Human Health, Dolph L. Hatfield, Ed.; Kluwer Academic. Publishers; Boston, MA.

[21] Bols, M., Lopez, O., \& Ortega-Caballero, F. (2007). In Kamerling, J. P., Ed., Comprehensive Glycoscience: From Chemistry to Systems Biology, Elsevier Science: Oxford, 1, 815-884.

[22] Soriano-Garcia, M. (2004). Organoselenium Compounds as Potential Therapeutic and Chemopreventive Agents: A review. Current. Medicinal Chem, 11, 1657-1169.

[23] Mugesh, G., du Mont, W.-W., \& Sies, H. (2001). Chemistry of Biologically Important Synthetic Organoselenium Compounds. Chemical Reviews, 101, 2125-2180.

[24] Rayman, M. P. (2005). Selenium in cancer prevention: a review of the evidence and mechanism of action. Proceedings of the Nutrition Society, 64, 527-542.

[25] Papp, L. V., Holmgren, A., \& Khanna, K. K. (2010). Selenium and Selenoproteins in Health and Disease. Antioxidants \& Redox Signaling, 12, 793-795.

[26] Jablonska, E., Gromadzinska, J., Sobala, W., Reszka, E., \& Wasowicz, W. (2008). Lung cancer risk associated with selenium status is modified in smoking individuals by Sep15 polymorphism. European Journal of Nutrition, 47, 47-54.

[27] Kryukov, G. V., Castellano, S., Novoselov, S. V., Lobanov, A. V., Zehtab, O., Guigo, R., et al. (2003). Characterization of mammalian selenoproteomes. Science, 300, 1439-1443.

[28] Ashton, K., Hooper, L., Harvey, L. J., Hurst, R., Casgrain, A., \& Fairweather-Tait, S. J. (2009). Methods of assessment of selenium status in humans: a systematic review. The American Journal of Clinical Nutrition, 89, 2025S-2039S.

[29] Ip, C., Dong, Y., \& Ganther, H. E. (2002). New concepts in selenium chemoprevention. Cancer and Metastasis Reviews, 21, 281-289.

[30] Schrauzer, G. N. (2009). Selenium and selenium-antagonistic elements in nutritional cancer prevention. Critical Reviews in Biotechnology, 29, 10-17.

[31] Evans, P., \& Halliwell, B. (2001). Micronutrients: oxidant/antioxidant status. British Journal of Nutrition, 85, 67S-74S.

[32] Wolf, G. (2005). The discovery of the antioxidant function of vitamin E: the contribution of Henry A. Matill. Journal of Nutrition, 135, 363-366. 
[33] Sies, H., \& Murphy, M. E. (1991). Role of tocopherols in the protection of biological systems against oxidative damage. Journal of Photochemistry and Photobiology, 8, 211-218.

[34] Brigelius-Flohe', R., \& Traber, M. G. (1999). Vitamin E: function and metabolism. The FASEB Journal, 13, 1145-1155.

[35] Yap, S. P., Yuen, K. H., \& Wong, J. W. (2001). Pharmacokinetics and bioavailability of alpha-, gamma-, and delta-tocotrienols under different food status. Journal of Pharmacy and Pharmacology, 53, 67-71.

[36] Yash, B. J., \& Pratico, D. (2012). Vitamin E in aging, dementia and Alzheimer's disease. Biofactors, 38, 90-97.

[37] Hacquebard, M., \& Carpentier, Y. A. (2005). Vitamin E: absorption, plasma transport and cell uptake. Current Opinion in Clinical Nutrition \& Metabolic Care, 8, 133-138.

[38] O’Byrne, D., Grundy, S., Packer, L., Devaraj, S., Baldenius, K., Hoppe, P. P., Kraemer, K., Jialal, I., \& Traber, M. G. (2000). Studies of LDL oxidation following alpha-, gamma-, or delta-tocotrienyl acetate supplementation of hypercholesterolemic humans. Free Radical Biology \& Medicine, 29, 834-845.

[39] Horiguchi, M., Arita, M., Kaempf-Rotzoll, D. E., Tsujimoto, M., Inoue, K., \& Arai, H. p. (2003). pH-dependent translocation of alpha-tocopherol transfer protein (alphaTTP) between hepatic cytosol and late endosomes. Genes Cells, 8, 789-800.

[40] Uchida, T., Abe, C., Nomura, S., Ichikawa, T., \& Ikeda, S. (2012). Tissue distribution of alfa- and gamma- tocotrienol and gama-tocopherol in rats and interference with their accumulation by alpha-tocopherol. Lipids, 47, 129-139.

[41] Kokarnig, S., Kuehnelt, D., Stiboller, M., Hartleb, U., \& Francesconi, K. A. (2011). Quantitative determination of small selenium species in human serum by HPLC/ ICPMS following a protein-removal, pre-concentration procedure. Analytical $\mathcal{E}$ Bioanalytical Chemistry, 400, 2323-2327.

[42] Suzuki, K. T., Kurasaki, K., Okazaki, N., \& Ogra, Y. (2005). Selenosugar, trimethylselenonium among urinary Se metabolites: dose- and agerelated changes. Toxicology and Applied Pharmacology, 206, 1-8.

[43] Klotz, L. O., Kroncke, K. D., Buchczyk, D. P., \& Sies, H. (2003). Role of copper, zinc, selenium, tellurium in the cellular defense against oxidative and nitrosative stress. Journal of Nutrition, 133, 1448S-1451S.

[44] Valko, M., Rhodes, C. J., Moncol, J., Izakovic, M., \& Mazur, M. (2006). Free radicals, metals, antioxidants in oxidative stress-induced cancer, Chemico-Biological Interactions, 160, 1-40.

[45] Susan, J. F. T., Yongping, B., Martin, R. B., Rachel, C., Dianne, F., John, E. H., et al. (2011). Selenium in human health and disease. Antioxidants E Redox Signaling, 14, 1337-1383. 
[46] Pasco, J. A., Jacka, F. N., Williams, L. J., Evans-Cleverdon, M., Sharon, L., Brennana, S. L., Kotowicza, M. A., Nicholsone, G. C., Ball, M. J., \& Berk, M. (2012). Dietary selenium and major depression: a nested case-control study. Complementary Therapies in Medicine, 20, 119-123.

[47] Maes, M., Galecki, P., Chang, Y. S., \& Berk, M. (2011). A review on the oxidative and nitrosative stress (O\&NS) pathways in major depression and their possible contribution to the (neuro) degenerative processes in that illness. Progress in Neuropsychopharmacology \& Biological Psychiatry, 35, 676-692.

[48] Ng, F., Berk, M., Dean, O., \& Bush, A. I. (2008). Oxidative stress in psychiatric disorders: evidence base and therapeutic implications. The International Journal of Neuropsycho- pharmacology, 11, 851-876.

[49] Berk, M., Ng, F., Dean, O., Dodd, S., \& Bush, A. I. (2008). Glutathione: a novel treatment target in psychiatry. Trends in Pharmacological Sciences, 29, 346-351.

[50] Herken, H., Gurel, A., Selek, S., Armutcu, F., Ozen, M. E., Bulut, M., et al. (2007). Adenosine deaminase, nitric oxide, superoxide dismutase, and xanthine oxidase in patients with major depression: impact of antidepressant treatment. Archives of Medical Research, 38, 247-252.

[51] Sarandol, A., Sarandol, E., Eker, S. S., Erdinc, S., Vatansever, E., \& Kirli, S. (2007). Major depressive disorder is accompanied with oxidative stress: short-term antidepressant treatment does not alter oxidativeantioxidative systems. Human Psychopharmacology, 22, 67-73.

[52] Whanger, P. D. (2001). Selenium and the brain: a review. Nutritional Neuroscience, 4, 81-97.

[53] Machado, M. S., Rosa, R. M., Dantas, A. S., Reolon, G. K., Appelt, H. R., Braga, A. L., et al. (2006). An organic selenium compound attenuates apomorphine-induced stereotypy in mice. Neuroscience Letters, 410, 198-202.

[54] Malhi, G. S., \& Berk, M. (2007). Does dopamine dysfunction drive depression? Acta Psychiatrica Scandinavica Supplement, 433, 116-124.

[55] Ishrat, T., Parveen, K., Khan, M. M., Khuwaja, G., Khan, M. B., Yousuf, S., et al. (2009). Selenium prevents cognitive decline and oxidative damage in rat model of streptozotocin-induced experimental dementia of Alzheimer's type. Brain Research, $1281,117-127$.

[56] Cardoso, B. R., Ong, T. P., Jacob-Filho, W., Jaluul, O., Freitas, M. I., \& Cozzolino, S. M. (2010). Nutritional status of selenium in Alzheimer's disease patients. British Journal of Nutrition, 103, 803-806.

[57] Finley, J. W., \& Penland, J. G. (1998). Adequacy or deprivation of dietary selenium in healthy men: clinical and psychological findings. Journal of Trace Elements in Experimental Medicine, 11, 1-27. 
[58] Mokhber, N., Namjoo, M., Tara, F., Boskabadi, H., Rayman, M. P., Ghayour-Mobarhan, M., et al. (2011). Effect of supplementation with selenium on postpartum depression: a randomized doubleblind placebo-controlled trial. Journal of Maternal-Fetal and Neonatal Medicine, 24, 104-108.

[59] ISAAC Steering Committee. (1998). Worldwide variation in prevalence of symptoms of asthma, allergic rhinoconjunctivitis, and atopic eczema: ISAAC. Lancet, 351, $1225-1232$.

[60] Allan, K., \& Devereux, G. (2011). Diet and asthma: nutrition implication from prevention to treatment. Journal of the American Dietetic Association, 111, 258-268.

[61] Comhair, S., Bhathena, P., Farver, C., Thunnissen, F., \& Srzurum, S. (2001). Extracellular glutathione peroxidase induction in asthmatic lungs: evidence for redox regulation of expression in human airway epithelial cells. FASEB Journal, 15, 70-78.

[62] Horváthovà, M., Jahnová, E., \& Gazdik, F. (1999). Effect of selenium supplementation in asthmatic subjects on the expression of endothelial cell adhesion molecules in culture. Biological Trace Element Research, 69, 15-26.

[63] Hasselmark, L., Malmgren, R., Zetterstrom, O., \& Unge, G. (1993). Selenium supplementation in intrinsic asthma. Allergy, 48, 30-36.

[64] Picado, C., Deulofeu, R., Lleonart, R., et al. (2001). Dietary micronutrients/antioxidants and their relationship with bronchial asthma severity. Allergy, 56, 43-49.

[65] Shaheen, S., Sterne, J., Thompson, R., Songhurst, C., Margetts, B., \& Burney, P. (2001). Dietary antioxidants and asthma in adults. Population-based case-control study. American Journal of Respiratory and Critical Care Medicine, 164, 1823-1828.

[66] Burney, P., Potts, J., Makowska, J., et al. (2008). A case-control study of the relation between plasma selenium and asthma in European populations: a GAL2EN project. [see comment][erratum appears in Allergy. 2008; 63 1647.], Allergy, 63, 865-871.

[67] Thomson, C. D., Wickens, K., Miller, J., Ingham, T., Lampshire, P., Epton, Town. G. I., Pattemore, P., \& Crane, J. (2012). Selenium status and allergic disease in a cohort of New Zealand children. Clinical \& Experimental Allergy, 42, 560-567.

[68] Nogueira, C. W., Zeni, G., \& Rocha, J. B. (2004). Organoselenium and organotellurium compounds: toxicology and pharmacology. Chemical Reviews, 104, 6255-6285.

[69] Silva Avila, D., Benedetto, A., Au, C., Manarin, F., Erikson, K., Antunes Soares, F., Teixeira Rocha, J. B., \& Aschner, M. (2012). Organotellurium and organoselenium compounds attenuate Mn-induced toxicity in Caenorhabditis elegans by preventing oxidative stress. Free Radical Biology \& Medicine, 52, 1903-1910.

[70] Fetoui, H., Mahjoubi-Samet, A., Jamoussi, K., Ellouze, F., Guermazi, F., \& Zeghal, N. (2006). Energy restriction in pregnant and lactating rats lowers bone mass of their progeny. Nutrition Research, 26, 421-426. 
[71] Moreno-Reyes, R., Egrise, D., Boelaert, M., Goldman, S., \& Meuris, S. (2006). Iodine deficiency mitigates growth retardation and osteopenia in selenium-deficient rats. Journal of Nutrition, 136, 595-600.

[72] Ren, F. L., Guo, X., Zhang, R. L., Wang, Sh. J., Zuo, H., Zhang, Z. T., et al. (2007). Effects of selenium and iodine deficiency on bone, cartilage growth plate and chondrocyte differentiation in two generations of rats. Osteoarthritis and Cartilage, 15, 1171-1177.

[73] Pahuja, D. N., \& De Luca, H. F. (1982). Thyroid hormone and vitamin D metabolism in the rat. Archives of Biochemistry and Biophysics, 213, 293-298.

[74] Amaraa, I. B., Troudia, A., Soudania, N., Guermazib, F., \& Zeghala, N. (2012). Toxicity of methimazole on femoral bone in suckling rats: Alleviation by selenium. Experimental and Toxicologic Pathology, 64, 187-195.

[75] UNAIDS. (2008). Report on the global AIDS epidemic. Geneva: UNAIDS.

[76] Fawzi, W. W., Msamanga, G. I., Spiegelman, D., et al. (2004). A randomized trial of multivitamin supplements and HIV disease progression and mortality. The New England Journal of Medicine, 351, 23-32.

[77] Diamond, A. M., Hu, J. Y., \& Mansur, D. B. (2001). Glutathione peroxidase and viral replication: Implications for viral evolution and chemoprevention. Biofactors, 14, 205-210.

[78] Pace, G. W., \& Leaf, C. D. (1995). The role of oxidative stress in HIV disease. Free Radical Biology \& Medicine, 19, 523-528.

[79] Stone, C. A., Kawai, K., Kupka, R., \& Fawzi, W. W. (2010). Role of selenium in HIV infection. . Nutrition Reviews , 68, 671-681.

[80] St Germain, D. L., Galton, V. A., \& Hernandez, A. (2009). Minireview: Defining the roles of the iodothyronine deiodinases: current concepts and challenges. Endocrinolo$g y, 150,1097-1107$.

[81] Zhang, S., Rocourt, C., \& Cheng, W-H. (2010). Selenoproteins and the aging brain. Mechanisms of Ageing and Development, 13, 253-260.

[82] Schweizer, U., Brauer, A. U., Kohrle, J., Nitsch, R., \& Savaskan, N. E. (2004). Selenium and brain function: a poorly recognized liaison. Brain Research Reviews, 45, 164-178.

[83] Hock, A., Demmel, U., Schicha, H., Kasperek, K., \& Feinendegen, L. E. (1975). Trace element concentration in human brain. Activation analysis of cobalt, iron, rubidium, selenium, zinc, chromium, silver, cesium, antimony and scandium. Brain, 98, 49-64.

[84] Prohaska, J. R., \& Ganther, H. E. (1976). Selenium and glutathione peroxidase in developing rat brain. Journal of Neurochemistry, 27, 1379-1387.

[85] Trapp, G. A., \& Millam, J. (1975). The distribution of ${ }^{75}$ Se in brains of selenium-deficient rats. Journal of Neurochemistry, 24, 593-595. 
[86] Nakayama, A., Hill, K. E., Austin, L. M., Motley, A. K., \& Burk, R. F. (2007). All regions of mouse brain are dependent on selenoprotein $\mathrm{P}$ for maintenance of selenium. Journal of Nutrition, 137, 690-693.

[87] Kyriakopoulos, A., Rothlein, D., Pfeifer, H., Bertelsmann, H., Kappler, S., \& Behne, D. (2000). Detection of small selenium-containing proteins in tissues of the rat. Journal of Trace Elements in Medicine and Biology, 14, 179-183.

[88] Hawkes, W. C., \& Hornbostel, L. (1996). Effects of dietary selenium on mood in healthy men living in a metabolic research unit. Biological Psychiatry, 39, 121-128.

[89] Ashrafi, M. R., Shabanian, R., Abbaskhanian, A., Nasirian, A., Ghofrani, M., Mohammadi, M., Zamani, G. R., Kayhanidoost, Z., Ebrahimi, S., \& Pourpak, Z. (2007). Selenium and Intractable Epilepsy: Is There Any Correlation? Pediatric Neurology, 36, 25-29.

[90] Rayman, M. P. (2000). The importance of selenium to human health. Lancet, 356, 233-241.

[91] Chen, J., \& Berry, M. J. (2003). Selenium and selenoproteins in the brain and brain diseases. Journal of Neurochemistry, 86, 1-12.

[92] Berry, M. J., Banu, L., \& Larsen, P. R. (1991). Type I iodothyronine deiodinase is a selenocysteine-containing enzyme. Nature, 349, 438-440.

[93] Hill, K. E., McCollum, G. W., Boeglin, M. E., \& Burk, R. F. (1997). Thioredoxin reductase activity is decreased in selenium deficiency. Biochemical and Biophysical Research Communications, 234, 293-295.

[94] Duntas, L. H. (2010). Selenium and the Thyroid: A Close-Knit Connection. The Journal of Clinical Endocrinology \& Metabolism, 95, 5180-5188.

[95] Hatfield, D. L., Yoo, M.-H., Carlson, B. A., \& Gladyshev, V. N. (2009). Selenoproteins that function in cancer prevention and promotion. Biochimica et Biophysica Acta, 1790, 1541-1545.

[96] Steinbrenner, H., \& Sies, H. (2009). Protection against reactive oxygen species by selenoproteins. Biochimica et Biophysica Acta, 1790, 1478-1485.

[97] Ip, C. (1998). Lessons from basic research in selenium and cancer prevention. Journal of Nutrition, 128, 1845-1849.

[98] Shamberger, R. J. (1970). Relationship of selenium to cancer: inhibitory effect of selenium on carcinogenesis. Journal of the National Cancer Institute, 44, 931-936.

[99] Clark, L. C., Combs, G. F., \& Turnbull, B. W. (1996). Effect of selenium supplementation for cancer prevention in patients with carcinoma of the skin: a randomized clinical trial. Journal of the American Medical Association, 279, 1975-1982.

[100] Bjelakovic, G., Nikolova, D., Simonetti, R. G., \& Gluud, C. (2008). Systematic review: primary and secondary prevention of gastrointestinal cancers with antioxidant supplements. Alimentary Pharmacology \& Therapeutics, 28, 689-703. 
[101] Brinkman, M., Buntinx, F., Muls, E., \& Zeegers, M. P. (2006). Use of selenium in chemo- prevention of bladder cancer. The Lancet Oncology, 7, 766-774.

[102] Lu, J., \& Jiang, C. (2005). Selenium and cancer chemoprevention: hypotheses integrating the actions of selenoproteins and selenium metabolites in epithelial and non-epithelial target cells. Antioxidants \& Redox Signaling, 7, 1715-1727.

[103] Waters, D. J., Shen, S., Glickman, L. T., Cooley, D. M., Bostwick, D. G., Qian, J., et al. (2005). Prostate cancer risk and DNA damage: translational significance of selenium supple- mentation in a canine model. Carcinogenesis, 26, 1256-1562.

[104] Battin, E. E., Perron, N. R., \& Brumaghim, J. L. (2006). The central role of metal coordination in selenium antioxidant acitivity. Inorganic Chemistry, 45, 499-501.

[105] Rayman, M. P. (2009). Selenoproteins and human health: Insights from epidemiological data. Biochimica et Biophysica Acta, 1790, 1533-1540.

[106] Bleys, J., Navas-Acien, A., \& Guallar, E. (2007). Serum selenium and diabetes in US adults. Diabetes Care, 30, 829-834.

[107] Akbaraly, T. N., Arnaud, J., Rayman, M. P., Hininger-Favier, I., Roussel, A. M., Berr, C., \& Fontbonne, A. (2010). Plasma selenium and risk of dysglycemia in an elderly French population: results from the prospective Epidemiology of Vascular Ageing Study. Nutrition $\mathcal{E}$ Metabolism, 7, 21-27.

[108] Bleys, J., Navas-Acien, A., \& Guallar, E. (2007). Selenium and diabetes: more bad news for supplements. Annals of Internal Medicine, 147, 271-272.

[109] Faure, P., Ramon, O., Favier, A., \& Halimi, S. (2004). Selenium supplementation decreases nuclear factor-kappa B activity in peripheral blood mononuclear cells from type 2 diabetic patients. European Journal of Clinical Investigation, 34, 475-481.

[110] Stranges, S., Marshall, T. R., \& Natarajan, R. (2007). Effects of long-term selenium supplementation on the incidence of type 2 diabetes: a randomized trial. Annals of Internal Medicine, 147, 217-223.

[111] Agarwal, A., \& Prabhakaran, S. A. (2005). Mechanism, measurement and prevention of oxidative stress in male reproductive physiology. Indian Journal of Experimental Biology, 43, 963-974.

[112] Hansen, J. C., \& Degachi, Y. (1996). Selenium and fertility in animals and men: a review, Acta Veterinaria Scandinavica, 37, 19-25.

[113] Wantanobe, T., \& Endo, A. (1991). Effects of selenium deficiency on spermmorphology and spermatocyte chromosomes in mice. Mutation Research, 262, 93-96.

[114] Olson, G. E., Winfrey, V. P., Hill, K. E., \& Burk, R. F. (2004). Sequential development of flagellar defects in spermatids and epididymal spermatozoa of selenium deficient rats. Reproduction, 127, 335-341. 
[115] Lenzi, A., Gandini, L., Lombardo, F., Picardo, M., Maresca, V., Panfili, E., et al. (2002). Polyunsaturated fatty acids of germ cell membranes, glutathione and blutathione dependent enzyme-PHGPx: from basic to clinic. Contraception, 65, 301-305.

[116] Hawkes, W. C., Alkan, Z., \& Wong, K. (2009). Selenium supplementation does not affect testicular selenium status and semen quality in North American men. Journal of Andrology, 30, 525-533.

[117] Seaton, A., Godden, D. J., \& Brown, K. (1994). Increase in asthma: a more toxic environment or a more susceptible population. Thorax, 49, 171-174.

[118] University of Maryland. Asthma [Online]. (2011). cited on August 10, 2011]. Available from URL: http://www.umm.edu/altmed/articles/asthma-000015.htm Citation Date= July 4, 2012].

[119] Kloner, A. R., Przyklenk, K., \& Whittaker, P. (1989). Deleterious effects of oxygen radicals in ischaemia-reperfusion: resolved and unresolved issue. Circulation, 80, $1115-1127$.

[120] Prithviraj, T., \& Misra, K. P. (2000). Reversal of atherosclerosis-fact or fiction? Cardiology Today, 4, 97-100.

[121] Sattler, W., Maiorino, M., \& Stocker, R. (1994). Reduction of HDL and LDL associated cholestrylester and phospholipids hydroperoxides by phospholipids hydroperoxideglutathione peroxidase and ebselen (Pz 51). Archives of Biochemistry and Biophysics, 309, 224.

[122] Ricetti, M. M., Guidi, G. C., Tecchio, C., et al. (1999). Effects of sodium selenite on in vitro interactions between platelets and endotelial cells. International Journal of Clinical and Laboratory Research, 29, 80-82.

[123] Kharb, S. (2003). Low blood glutathione levels in acute myocardial infarction. Indian Journal of Medical Sciences, 57, 335-337.

[124] Riaz, M., \& Mehmood, K. T. (2012). Selenium in human health and disease: a review. Journal of Postgraduate Medical Institute, 26, 120-133.

[125] Suleyman, Ö., Mustafa, N., Mesut, Ç., Vedat, B., \& Flores-Arce, M. F. (2011). Effects of Different Medical Treatments on Serum Copper, Selenium and Zinc Levels in Patients with Rheumatoid Arthritis. Biological Trace Element Research, 142, 447-455.

[126] Peretz, A., Siderova, V., \& Neve, J. (2001). Selenium supplementation in rheumatoid arthritis investigated in a double blind, placebo- controlled trial. Scandinavian Journal of Rheumatology, 30, 208-212.

[127] Cunningham, F. G., \& Lindheimer, M. D. (1992). Hypertension in Pregnancy: Current concepts. The New England Journal of Medicine, 326, 927-932.

[128] Sharma, J. B. (2001). Benefits of Selenium during pregnancy. Obstetrics and Gynaecolo$g y, 6,459-462$. 
[129] Barrington, J. W., Lindsay, P., Names, D., Smith, S., \& Robert, A. (1996). Selenium deficiency and miscarriage: a possible link? British Journal of Obstetrics and Gynecology, 2, 130-132.

[130] Tinggi, U. (2008). Selenium: its role as antioxidant in human health. Environmental Health and Preventive Medicine, 13, 102-108.

[131] Beck, M. A. (2001). Antioxidants and viral infections: host immune response and viral pathogenicity. Journal of the American College of Nutrition, 20, 384S-388S.

[132] Beck, M. (2006). Selenium, viral infections. Hatfield DL, Berry MJ, Gladyshev VN, editors, Selenium: its molecular biology and role in human health, New York: Springer, 287-298.

[133] Broome, C. S., McArdle, F., Kyle, J. A., Andrews, F., Lowe, N. M., Hart, C. A., et al. (2004). An increase in selenium intake improves immune function and poliovirus handling in adults with marginal selenium status. The American Journal of Clinical Nutrition, 80, 154-162.

[134] Baum, M. K., \& Campa, A. (2006). Role of selenium in HIV/AIDS. In: Hatfield DL, Berry MJ, Gladyshev VN, editors. Selenium- its molecular biology and role in human health, New York: Springer, 299-310.

[135] McKenzie, R. C., Beckett, G. J., \& Arthur, J. R. (2006). Effects of selenium on immunity and aging. In: Hatfield DL, Berry MJ, Gladyshev VN editors. Selenium-its molecular biology and role in human health, New York: Springer, 287-298.

[136] Sheweita, S. A., \& Koshhal, K. (2007). Calcium metabolism and oxidative stress in bone fractures: role of antioxidants. Current Drug Metabolism, 8, 519-525.

[137] Finkel, T., \& Holbrook, N. J. (2000). Oxidants, oxidative stress and biology of ageing. Nature, 408, 147-239.

[138] Cetinus, E., Kilinc $c_{s}$ M., Uzel, M., Inanc ${ }_{s}$, F., Kurutas, E. B., Bilgic, E., et al. (2005). Does long-term ischemia affect the oxidant status during fracture healing? Archives of Orthopedic and Trauma Surgery, 125, 376-380.

[139] Sandukji, A., Al-Sawaf, H., Mohamadin, A., Alrashidi, Y., \& Sheweita, S. A. (2010). Oxidative stress and bone markers in plasma of patients with long-bone fixative surgery: Role of antioxidants. Human and Experimental Toxicology, 30, 435-442.

[140] Azzi, A., Aratri, E., Boscoboinik, D., Clement, S., Ozer, N. K., Ricciarelli, R., \& Spycher, S. (1998). Molecular basis of $\alpha$-tocopherol control of smooth muscle cell proliferation. Biofactors, 7, 3-14.

[141] Brigelius-Flohe', R., \& Galli, F. (2010). Vitamin E: A vitamin still awaiting the detection of its biological function. Mol. Nutr. Food Res., 54, 583-587.

[142] Cicek, N., Eryilmaz, O. G., Sarikaya, E., Gulerman, C., \& Genc, Y. (2012). Vitamin E effect on controlled ovarian stimulation of unexplained infertile women. Journal of Assisted Reproduction and Genetics, 29, 325-328. 
[143] Khanna, S., Parinandi, N. L., Kotha, S. R., Roy, S., Rink, C., Bibus, D., \& Sen, C. K. (2010). Nanomolar vitamin E alpha-tocotrienol inhibits glutamate-induced activation of phospholipase A2 and causes neuroprotection. Journal of Neurochemistry, 112, 1249-1260.

[144] Reiter, E., Jiang, Q., \& Christen, S. (2007). Anti-inflammatory properties of alpha- and gamma-tocopherol. Molecular Aspects of Medicine, 28, 668-691.

[145] Naito, Y., Shimozawa, M., Kuroda, M., Nakabe, N., Manabe, H., Katada, K., Kokura, S., Ichikawa, H., Yoshida, N., Noguchi, N., \& Yoshikawa, T. (2005). Tocotrienols reduce 25-hydroxycholesterol-induced monocyteendothelial cell interaction by inhibiting the surface expression of adhesion molecules. Atherosclerosis, 180, 19-25.

[146] Burlakova, E. B., Krashakov, S. A., \& Khrapova, N. G. (1998). The role of tocopherols in biomembrane lipid peroxidation. Membrane and Cell Biology, 12, 173-211.

[147] Coquette, A., Vray, B., \& Vanderpas, J. (1986). Role of vitamin E in the protection of the resident macrophage membrane against oxidative damage. Archives Internationales de Physiologie. de Biochimie et de Biophysique, 94 ., 29S-34S.

[148] Pratico, D., Tangirala, R. K., Rader, D. J., Rokach, J., \& FitzGerald, G. A. (1998). Vitamin E suppresses isoprostane generation in vivo and reduces atherosclerosis in ApoE-deficient mice. Nature Medicine, 4, 1189-1192.

[149] Moriguchi, S., \& Muraga, M. (2000). Vitamin E and immunity. Vitamins \& Hormones, 59, 305-336.

[150] $\mathrm{Wu}, \mathrm{D}$., et al. (2000). In vitro supplementation with different tocopherol homologues can affect the function of immune cells in old mice. Free Radical Biology \& Medicine, $28,643-651$.

[151] Palamanda, J. R., \& Kehrer, J. P. (1993). Involvement of vitamin E and protein thiols in the inhibition of microsomal lipid peroxidation by glutathione. Lipids, 28, 427-431.

[152] Agarwal, A., \& Sekhon, L. H. (2011). Oxidative stress and antioxidants for idiopathic oligoasthenoteratospermia: is it justified? Indian Journal of Urology, 27(1), 74-85.

[153] Bouayed, J., \& Bohn, T. (2010). Exogenous antioxidants-double-edged swords in cellular redox state. Health beneficial effects at physiologic doses versus deleterious effects at high doses. Oxidative Medicine and Cellular Longevity, 3, 228-237.

[154] Chappell, L. C., Seed, P. T., Briley, A. L., et al. (1999). Effect of antioxidants on the occurrence of pre-eclampsia in women at increased risk: a randomized trial. Lancet, $354,810-816$.

[155] Fairfield, K. M., \& Fletcher, R. H. (2002). Vitamins for chronic disease prevention in adults: scientific review. Journal of the American Medical Association, 287, 3116-3126.

[156] Forstrom, J. W., Zakowski, J. J., \& Tappel, A. L. (1978). Identification of the catalytic site of rat liver glutathione peroxidase as selenocysteine. Biochemistry, 17, 2639-2644. 
[157] Tamura, T., \& Stadtman, T. C. (1996). A new selenoprotein from human lung adenocarcinoma cells: purification, properties, and thioredoxin reductase activity. Proceedings of the National Academy of Sciences, 93, 1006-1011.

[158] Kiremidjian-Schumacher, L., Roy, M., Wishe, H. I., Cohen, M. W., \& Stotzky, G. (1994). Supple- mentation with selenium and human immune cell functions. II. Effect on cytotoxic lymphocytes and natural killer cells. Biological Trace Element Research, 41, 115-127.

[159] Baker, S. S., \& Cohen, H. J. (1983). Altered oxidative metabolism in selenium-deficient rat granulocytes. The Journal of Immunology, 130, 2856-2860.

[160] Sakaguchi, S., et al. (2000). Roles of selenium in endotoxin-induced lipid peroxidation in the rats liver and in nitric oxide production in J774A. 1 cells. Toxicology Letters, $118,69-77$.

[161] Kim, S. H., Johnson, V. J., Shin, T. Y., \& Sharma, R. P. (2004). Selenium attenuates lipopoly- saccharide-induced oxidative stress responses through modulation of p38 MAPK and NF-kappaB signaling pathways. Experimental Biology and Medicine, 229, 203-213.

[162] Maehira, F., Miyagi, I., \& Eguchi, Y. (2003). Selenium regulates transcription factor NF-kappaB activation during the acute phase reaction. Clinica Chimica Acta, 334, 163-171.

[163] Beck, M. A., \& Matthews, C. C. (2000). Micronutrients and host resistance to viral infection. Proceedings of the Nutrition Society, 59, 581-585.

[164] Ip, C., \& Medina, D. (1987). Current concepts of selenium and mammary tumorigenesis. Medina D, Kidwell W, Heppner GH, Anderson E, editors, Cellular and molecular biology of mammary cancer, New York: Plenum press, 479.

[165] Ip, C., \& Daniel, F. B. (1985). Effects of selenium on 7, 12 di-methyl benzanthracene induced mammary carcinogenesis and DNA adduct formation. Cancer Research, 45, 61-68.

[166] Lotan, Y., Goodman, P. J., Youssef, R. F., Svatek, R. S., Shariat, S. F., Tangen, C. M., Thompson, I. M. Jr., \& Klein, E. A. (2012). Evaluation of Vitamin E and Selenium Supplementation for the Prevention of Bladder Cancer in SWOG Coordinated SELECT. The Journal of Urology, 187, 2005-2010.

[167] Jemal, A., Siegel, R., Xu, J., et al. (2010). Cancer statistics. CA A Cancer Journal of Clinicians, 60, 277-300.

[168] Samanic, C., Kogevinas, M., Dosemeci, M., Malats, N., Real, F. X., Garcia-Closas, M., Serra, C., Carrato, A., et al. (2006). Smoking and bladder cancer in Spain: effects of tobacco type, timing, environmental tobacco smoke, and gender. Cancer Epidemiology, Biomarkers and Prevention, 15, 1348-1354. 
[169] Botteman, M. F., Pashos, C. L., Redaelli, A., et al. (2003). The health economics of bladder cancer: a Comprehensive review of the published literature. Pharmacoeconomics, 21, 1315-1330.

[170] Amaral, A. F. S., Cantor, K. P., Silverman, D. T., \& Malats, N. (2010). Selenium and bladder cancer risk: a meta-analysis. Cancer Epidemiol Biomarkers Prev, 19, 2407-2415.

[171] Bardia, A., Tleyjeh, I. M., Cerhan, J. R., et al. (2008). Efficacy of antioxidant supplementation in reducing primary cancer incidence and mortality: systematic review and meta-analysis. Mayo Clinic Proceedings, 83, 23-34.

[172] Lippman, S. M., et al. (2009). Effect of selenium and vitamin E on risk prostate cancer and other cancers: the Selenium and Vitamin E Cancer Prevention Trial (SELECT). Journal of American Medical Association, 301, 39-51.

[173] Ledesma, M. C., Jung-Hynes, B., Schmit, T. L., Kumar, R., Mukhtar, H., \& Ahmad, N. (2011). Selenium and vitamin E for prostate cancer: Post-SELECT (Selenium and Vitamin E Cancer Prevention Trial) status. Molecular Medicine, 17, 134-143.

[174] Beck, M. A. (2007). Selenium and vitamin E Status: Impact on viral pathogenicity. The Journal of Nutrition, 137, 1338-1340.

[175] Jiang, L., Yang, K-h., Tian, J-h., et al. (2010). Efficacy of Antioxidant Vitamins and Selenium Supplement in Prostate Cancer Prevention: A Meta-Analysis of Randomized Controlled Trials. Nutrition and Cancer, 62, 719-727.

[176] Jin, X., Hidiroglou, N., Lok, E., Taylor, M., Kapal, K., et al. (2012). Dietary Selenium (Se) and Vitamin E (VE) Supplementation Modulated Methylmercury-Mediated Changes in Markers of Cardiovascular Diseases. Rats Cardiovascular Toxicology, 12, $10-24$.

[177] El-Desoky, G., Abdelreheem, M., AL-Othman, A., Alothman, Z., Mahmoud, M., \& Yusuf, K. (2012). Potential hepatoprotective effects of vitamin E and selenium on hepatotoxicity induced by malathion in rats. African Journal of Pharmacy and Pharmacology, 6, 806-813. 